\title{
Use of additive technologies for metal injection molding
}

\author{
A.Yu. Korotchenko ${ }^{a}$, D.E. Khilkov ${ }^{a}$, M.V. Tverskoy ${ }^{a^{*}}$ and A.A. Khilkova ${ }^{a}$
}

${ }^{a}$ Department of Casting Technology, Bauman Moscow State Technical University, Moscow, 105005, Russia

\begin{tabular}{l}
\hline A R T I C L EI N F O \\
\hline Article history: \\
Received 28 August 2019 \\
Accepted 8 October 2019 \\
Available online \\
8 October 2019 \\
\hline Keywords: \\
Additive manufacturing \\
MIM technology \\
Feedstock \\
Fused Filament Fabrication \\
Binder Jet \\
3D printer
\end{tabular}
\begin{abstract}
A B S T R A C T
The paper is concerned with the cost reduction of the elements' production according to the metal injection molding technology of metal powder mixtures (MIM), using the additive technologies (AT) for the production of the green part. This method allows obtaining high fidelity of the materials both in mass production and in one of a kind, and small-series production because it is not necessary to the production of expensive casting press mold of metal powder mixture on the injection molding machine. In his paper, the author showed the advantages and disadvantages of two AT technologies which directly use materials for MIM technology: the technology of fused filament fabrication (Fused Filament Fabrication - FFF) and the technology of Binder Jet (BJ). The author proposes to reduce costs reduction of manufacturing filament for $3 \mathrm{D}$ printing according to the FFF technology of green part using already existing feedstock as the basis. The manufacturing technology of the filament is shown by the example of the feedstock steel 316LW BASF. The specific character of the technology is a limited amount of polyoxymethylene (POM) and low-density polyethylene (LDPE) is introduced into the standard composition of the feedstock to increase its plasticity. The author presented the results of tensile testing of items manufactured by standard technology and using AT technologies. Some reduction in the strength characteristics of the items with the using AT technologies is primarily due to the printing modes. The optimization of print modes allows obtaining the properties of the items, not inferior items by standard technology.
\end{abstract}

\section{Introduction}

The development of production is primarily associated with the use of advanced technologies. In the paper (Courtesy McKinsey \& Company, 2018), 10 such technologies were identified, among which additive technologies (AT) and MIM technologies (Metal Injection Molding) occupy the first and second places, respectively. Until recently, a significant limitation on the use of MIM technology was the high cost of manufacturing parts for single and small-scale production. It depended mainly on the high cost of equipment at the stage of rigging a green part. The use of AT at the stage of manufacturing a green part reduces the cost of production and significantly expands the scope of use of MIM technology (Williams, N., 2018; Williams, B., 2018; Moritz et al., 2018; Lednev et al., 2019; Kuznetsov et al., 2018; Gorodetskii et al., 2018; Lychev et al., 2018; Lengauer et al., 2019; Johnson, 2018). Fig. 1 shows the mutual influence of different technologies and blurring the boundaries between them (Williams, B., 2018).

* Corresponding author.

E-mail addresses: tversk@bmstu.ru (M.V. Tverskoy) 


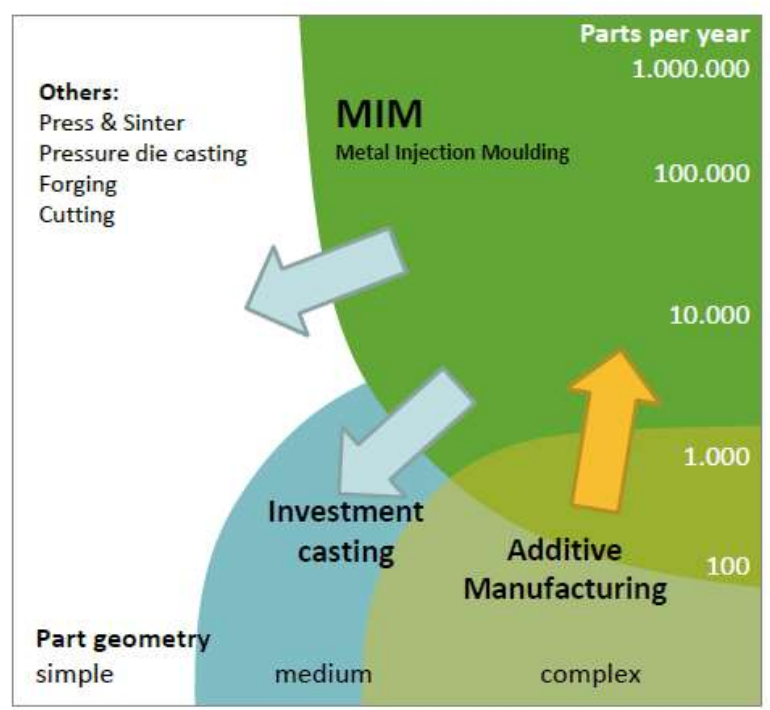

Fig. 1. The mutual influence of MIM technology and AT (Petzoldt, 2018)

Of the entire variety of ATs, there are only two technologies that are directly related to the materials used in the MIM technology - this is the technology for the production of molten filament (Fused Filament Fabrication - FFF) (Wu et al., 2002; Wolff et al., 2019; Gibson et al., 2018), and jet binder application (BinderJet) (Williams, N., 2018; Dizon et al, 2018; Ngo et al., 2018). With FFF technology, a metal powder mixture (feedstock) is directly used for MIM technology, and in BinderJet technology, powder and binder are used separately (Williams, N., 2018; Digital Metal, 2019; ExOne, 2016, 2018; BASF, 2018). The advantages and disadvantages of these two technologies are discussed in detail in (Williams, N., 2018; BASF, 2018). We single out the main ones:

- efficiency - BinderJet technology can be used for the manufacture of small, and in the future mediumsized series of parts, which indicates its high efficiency;

- integrability with MIM-technology - FFF technology is fully integrated into MIM-technology and does not require additional equipment and materials;

- environmental friendliness - finely dispersed metal powder is mixed with polymers and does not pose a risk to human health and the environment in the manufacture of products;

- dosing accuracy - particles of metal powder are evenly distributed over the volume of the polymer binder, which greatly facilitates the dosage of the powder, according to the FFF technology, in comparison with the distribution of the powder on the working surface when using BinderJet technology;

- the cost of machine time - according to (Munsch, 2018), the cost of one hour of machine time using FFF technology is $3 \ldots 5 €$, and according to BinderJet technology - $35 \ldots 50 €$;

- print quality - surface roughness of parts using BinderJet technology is 2 times less (Munsch, 2018), dimensional accuracy is determined by the resolution capability of a 3D printer: according to DigitalMetal (Digital Metal, 2019), which implements BinderJet technology, the resolution in the Zaxis direction is $35 \mu \mathrm{m}$, for printers using FFF technology this value is usually higher than $50 \mu \mathrm{m}$;

- mechanical properties - the density values of parts manufactured using BinderJet technology, their surface hardness, and tensile strength are slightly higher (Munsch, 2018) than with FFF technology;

Thus, BinderJet and FFF technologies complement each other and can be effectively used for the production of green parts for MIM technology in both single and small series production. A number of studies (Kukla et al., 2016; Burkhardt et al., 2016; Awad et al., 2016; Gonzalez-Gutierrez et al., 2016) present the results of studies related to the production of filament from feedstock and its use to obtain green parts using FFF technology. All studies used 316L steel feedstock. It was also pointed out that 3D printing modes have a significant impact on the quality of green parts. In addition, according to (Munsch, 
2018), the cost of a filament for 3D printing is significantly higher than for conventional MIM technology: $15 \ldots 18 €$ per $1 \mathrm{~kg}$ for 316L steel grade, and for BASF Ultrafuse 316LX filament - $200 €$ per $1 \mathrm{~kg}$. The price of filament from other suppliers is about $100 €$ per $1 \mathrm{~kg}$. All this testifies to the relevance of further work aimed at reducing the cost of the filament and optimizing the 3D printing modes.

The purpose of the work is to develop the feedstock composition of $316 \mathrm{~L}$ steel for the manufacture of raw cast billets using FFF technology, to study the basic properties of filaments for printing on a 3D printer, and to assess the effect of printing on the properties of raw cast billets.

\section{Initial data and experiment}

To develop the composition of the filament for printing on a 3D printer, BASF steel feedstock 316LW was chosen as the main component. Typical chemical composition of parts after sintering is as follows (BASF, 2003):

$$
\begin{gathered}
\mathrm{C}-\geq 0.03 \quad \mathrm{Mn}-\leq 2 \\
\mathrm{Cr}-16 \ldots 18 \quad \mathrm{Mo}-2 \ldots 3 \\
\mathrm{Ni}-10 \ldots 14 \quad \mathrm{Si}-\leq 1 \\
\mathrm{Fe}-\text { Balance }
\end{gathered}
$$

The main characteristics of the feedstock are given in the table.

The main characteristics of the feedstock

\begin{tabular}{lllll}
\hline Parameter & Unit & Typical value & Specification & Test Method \\
\hline MFI & $\mathrm{g} / 10 \mathrm{~min}$ & 950 & $300 \ldots 1300$ & ISO $1133\left(190{ }^{\circ} \mathrm{C}, 21.6 \mathrm{~kg}\right)$ \\
Density & $\mathrm{g} / \mathrm{cm}^{3}$ & 7.90 & $\geq 7.95$ & ISO 3369 \\
Oversizing Factor & & 1.1669 & $1.1629 \ldots 1.1710$ & RC/PQ-SH-1360 \\
\hline
\end{tabular}

Numerous works (Amin et al., 2017; Kong et al., 2012; Hamidi et al., 2017; Raza et al., 2016) are devoted to the selection of the optimal ratio of metal powder and binder in the feedstock. All researchers adhere to approximately the same ratio of powder and binder - at the level of 60 to $40 \%$ (by volume). This ratio in terms of mass gives in feedstock about $90 \%$ of the powder or more. A high powder content leads to a low yield index (see Table 2), which is associated with a high feedstock viscosity in the molten state (Korotchenko et al., 2018; Zheng et al., 2011; Raymond, 2012). To mix the binder and powder components in the manufacture of feedstock, a laboratory twin-screw mixer was used (Fig. 2).

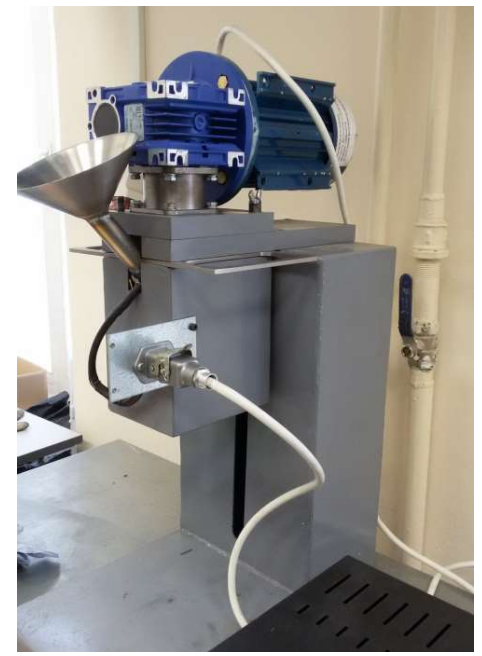

Fig. 2. Laboratory twin-screw mixer 
Filament elongates on a laboratory press through a specialized die (Fig. 3).

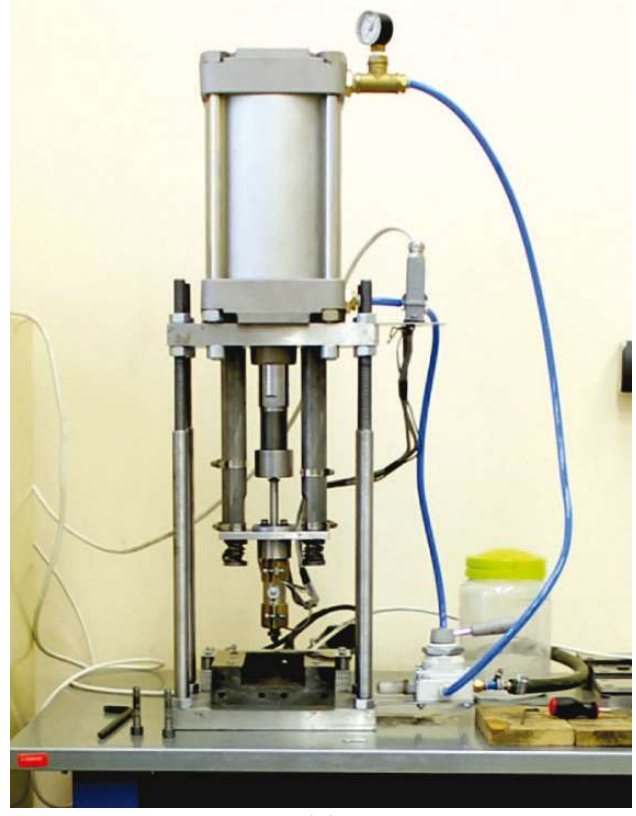

(a)

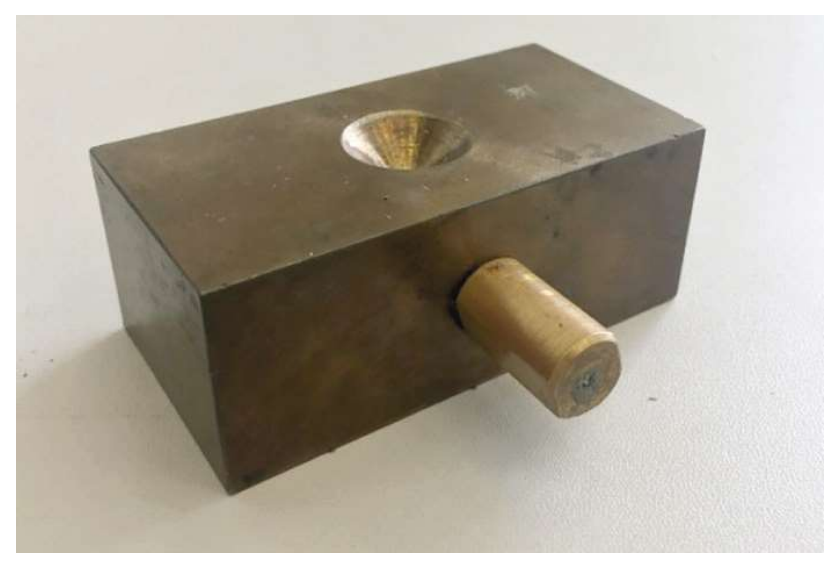

(b)

Fig. 3. Laboratory press (left) and die (right)

At the exit of the die, the filament was cooled by running water in an inclined trough, which excluded its extension and made it possible to obtain a filament of constant diameter. The diameter of the elongated filament was $1.75 \mu \mathrm{m}$. To print green parts, we used a 3D printer Designer-X-Pro from PICASO-3D manufactured in Russia (Fig. 4).

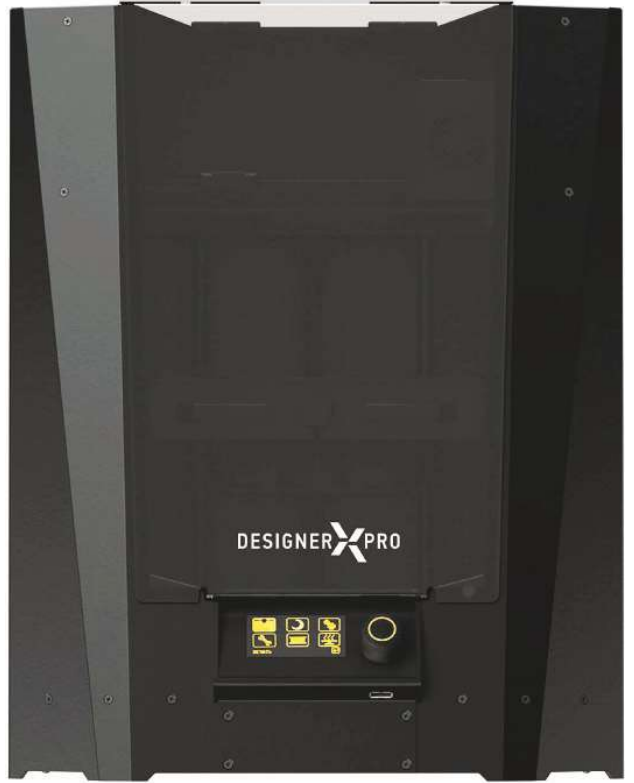

(a)

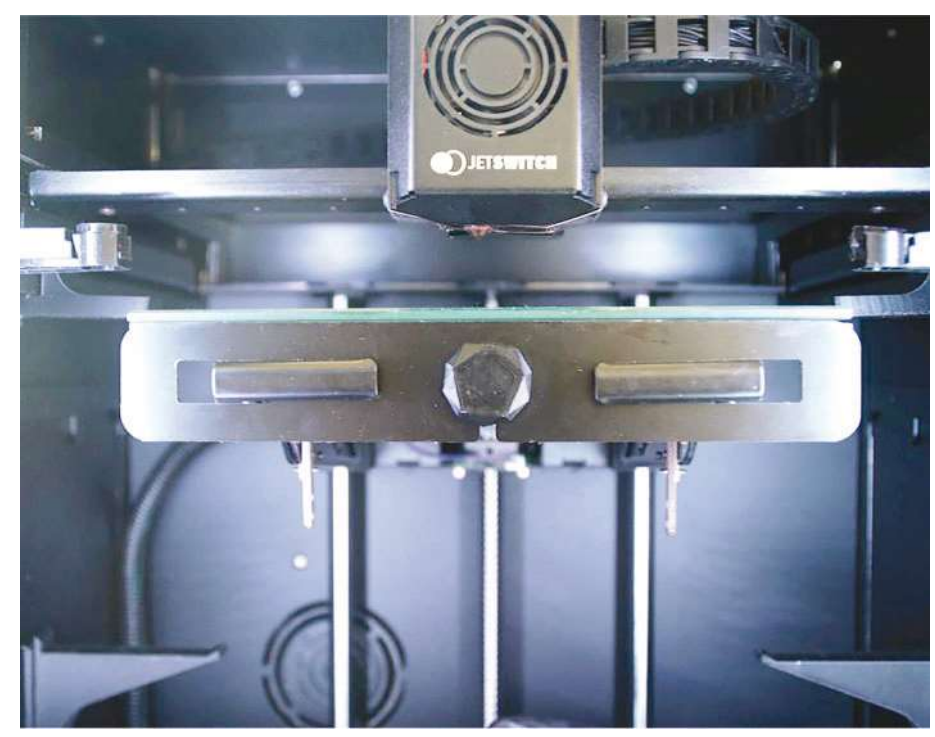

(b)

Fig. 4. 3D-printer Designer -X-Pro: $a$ - general view; $b$ - printing platform

Printer specifications: number of nozzles - 2; support - soluble; printing area - $200 \times 200 \times 210 \mathrm{~mm}$; print speed - up to $100 \mathrm{sm}^{3} / \mathrm{h}$; nozzle diameter - $0,3 \mathrm{~mm}$; print resolution - $50 \ldots . .250 \mu \mathrm{m}$; positioning accuracy - XY: $11 \mu \mathrm{m}, \mathrm{Z}: 1.25 \mu \mathrm{m}$; filament diameter - $1.75 \pm 0,1 \mathrm{~mm}$; maximum printing temperature: $380{ }^{\circ} \mathrm{C}$; maximum table temperature $-150^{\circ} \mathrm{C}$. 


\section{Research results. Discussion}

The quality of the manufactured filament was evaluated by two parameters - tensile strength and bending strength. The first parameter is used to assess the tensile strength of the filament when pulling the filament through the extruder of a 3D printer. The second parameter gives an assessment of the elasticity of the filament at the time the filament is fed into the extruder of the $3 \mathrm{D}$ printer.

The experiments showed that the filament obtained from the $316 \mathrm{LW}$ feedstock for standard MIM technology breaks even with a slight bend. To increase the elasticity, the feedstock was mixed with an additional polyoxymethylene (POM) and low-density polyethylene (LDPE) at a temperature of $170{ }^{\circ} \mathrm{C}$. The more binder was added, the higher the elasticity of the filament was. However, with an increase in the amount of binder, the fraction of powder in the feedstock decreases, which leads to an increase in shrinkage of parts during sintering and to the likelihood of shrinkage defects, as well as to a decrease in dimensional accuracy. As a result of the studies, satisfactory elasticity of filament was obtained with a scale factor of 1.24. Fig. 5 shows two filament - one obtained from 316LW feedstock, the second with the addition of a binder (feedstock 316LW P).

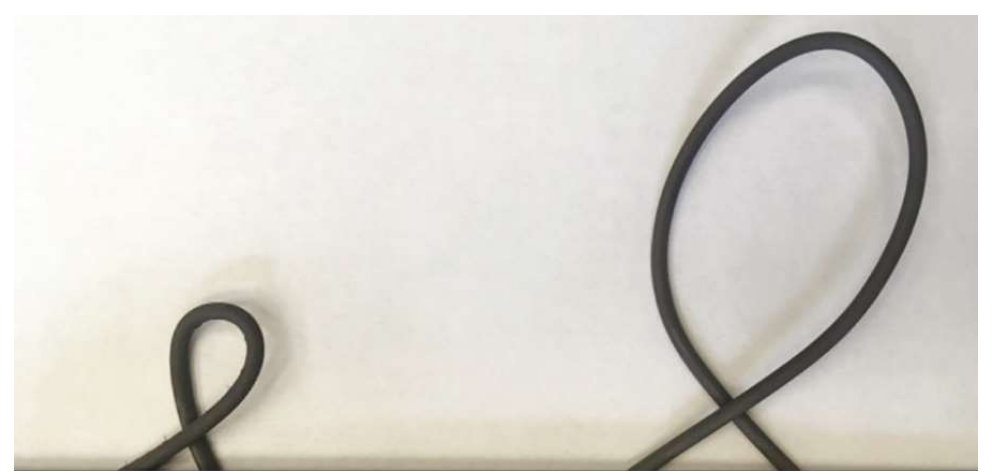

Fig. 5. Filament from feedstocks 316LWP (left) and 316LW (right)

As seen from Fig. 5, filament from feedstock 316LWP has much greater elasticity and does not break with significant bends. Further studies showed that the addition of POM and LDPE in different ratios significantly affects the strength of the filament. Fig. 6 shows the results of filament tensile tests at different ratios of POM and LDPE. The tests were carried out on a universal electromechanical tensile testing machine brand FP-10.

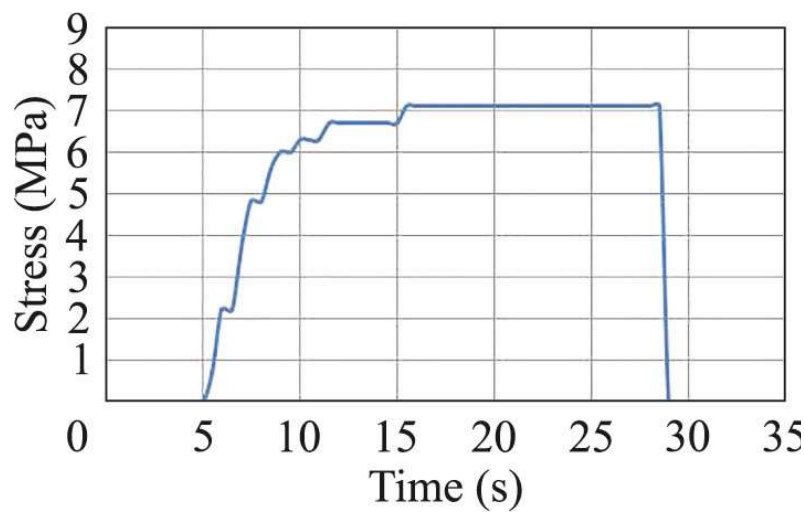

(a)

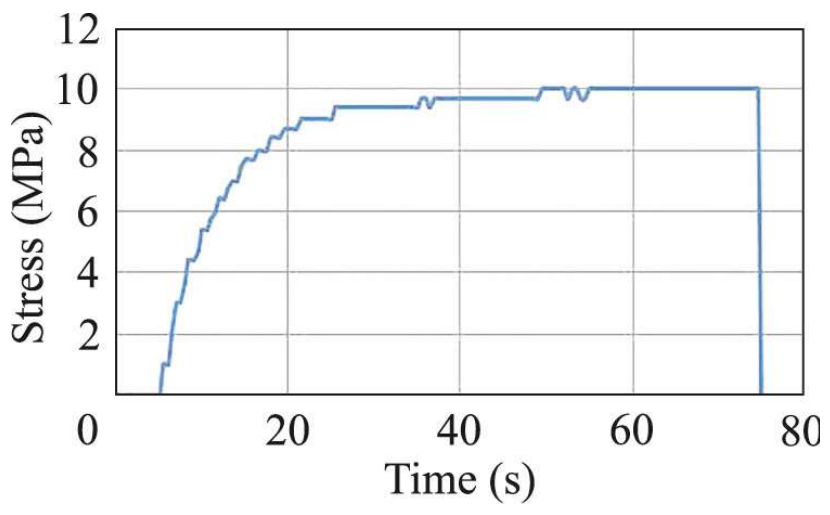

(b)

Fig. 6. Filament load curves on a tensile testing machine: $a$ - tensile strength $7 \mathrm{MPa}$, POM: LDRE ratio - 85:15 (\%wt); $b$ - tensile strength $10 \mathrm{MPa}$, POM: LDRE ratio - 95:5 (\%wt) 
The more POM was in the binder composition, the greater was the filament tensile strength. The manufacturers of feedstock as the main characteristics indicate the tensile strength and hardness of the samples after sintering. To determine the strength characteristics, test samples were made (Fig. 7).

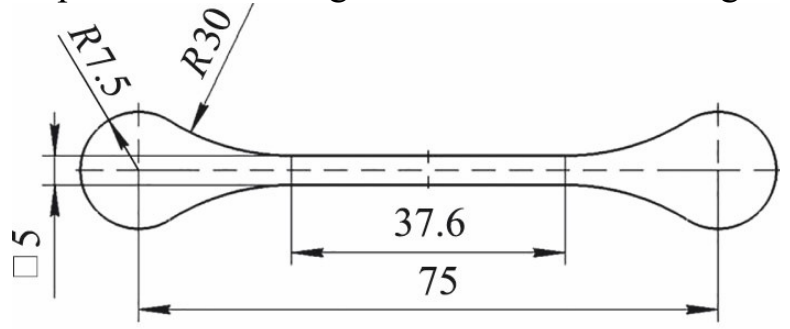

(a)

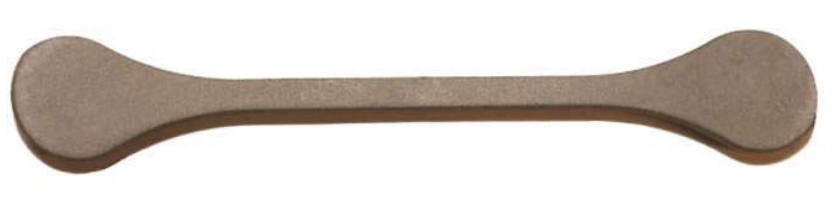

(b)

Fig. 7. Drawing $(a)$ of the manufactured sample and the sample itself $(b)$

Test samples were divided into two groups, differing only in the method of manufacturing raw samples, and using the MIM technology, a raw sample was made, the binder was smelted and the sample was sintered. Green parts of the first group were obtained on a Wittmann Battenfeld injection molding machine (IMM) from feedstock 316LW, which belongs to the Smart Power series, machine type 50/60. Green parts of the second group were printed on a Designer-X-Pro 3D printer from feedstock 316LW R. Fig. 8 shows the results of tensile testing of samples.

\section{IMM}
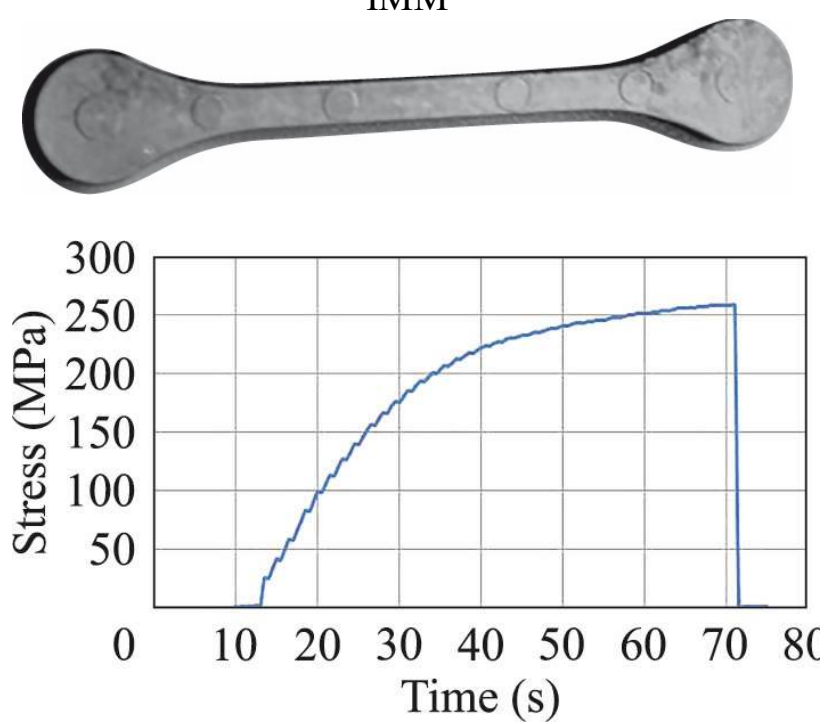

(a)
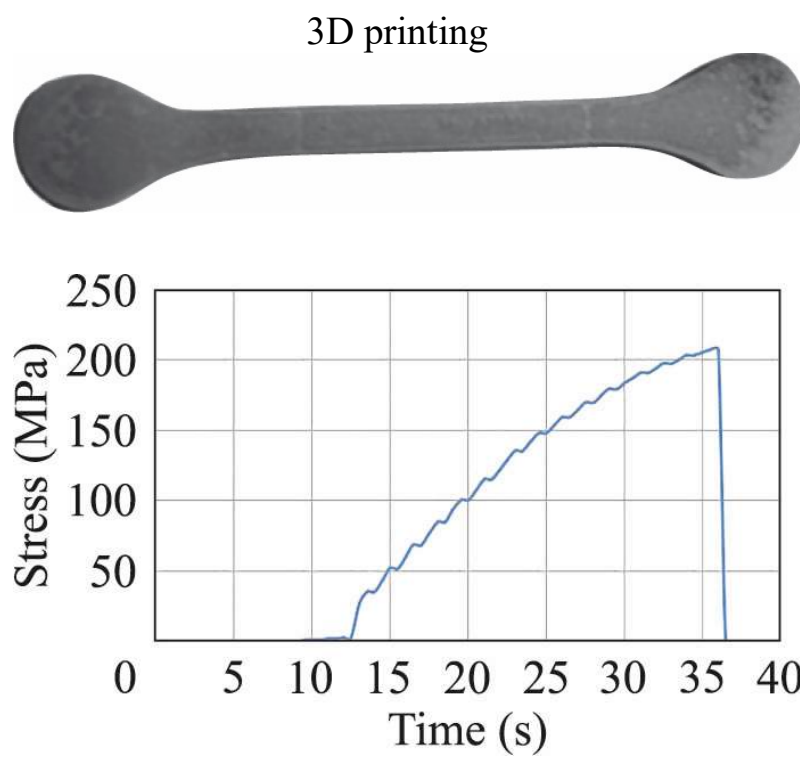

(b)

Fig. 8. Tensile Test Results: $a$ - injection molding machine, tensile strength $251 \mathrm{MPA} ; b-$ 3D printing, tensile strength $207 \mathrm{MPa}$

The low absolute values of the tensile strength are associated with the features of the experimental mode of sintering of the samples (sintering temperature below $1350^{\circ} \mathrm{C}$, sintering time less than $1 \mathrm{~h}$ ), which made it possible to conduct a large number of experiments in a short time. The main goal, in this case, is to assess the relative values of the tensile strength between the two methods of manufacturing raw samples.

A decrease in the tensile strength by $18 \%$ for samples printed on a 3D printer is primarily associated with printing modes. The printing modes are influenced by many factors, among which it is necessary to note the print temperature, the feed rate of the filament to the print head and print speed. By controlling these factors, it is possible to significantly increase the mechanical and operational properties of parts printed on a $3 \mathrm{D}$ printer. 


\section{Conclusions}

The use of AT at the stage of manufacturing green parts for MIM technology allows you to use all the advantages of this technology in a single and small-scale production of precision parts. BinderJet and FFF technologies are easily integrated into MIM technology, complement each other and can be effectively used for the production of green parts. In order to reduce the cost of filament for 3D printing, in this paper it is proposed to use a standard feedstock for MIM technology with an additional amount of binder, which does not require significant production costs and is easily implemented in practice. Tests of parts printed on a 3D printer from a new feedstock showed a satisfactory level of their mechanical properties. Optimization of printing modes will significantly increase the level of mechanical properties of parts printed on a $3 \mathrm{D}$ printer.

\section{References}

Amin, A. M., Ibrahim, M. H. I., Hashim, M. Y., Marwah, O. M. F., Othman, M. H., Johar, M. A., \& Ng, C. H. (2017). Green density optimization of stainless steel powder via metal injection molding by Taguchi method. In MATEC Web of Conferences (Vol. 135, p. 00038). EDP Sciences.

Awad, A., Trenfield, S. J., Goyanes, A., Gaisford, S., \& Basit, A. W. (2018). Reshaping drug development using 3D printing. Drug discovery today, 23(8), 1547-1555.

BASF (2003). Technical Information: Catamold $\AA$, on http://www.catamold.de/cm/internet/Catamold/en/content/Microsite/Catamold/Technische_Informat ionen_Catamold_Specifications

BASF (2018). Ultrafuse 316LX: BASF's 'Catamold ${ }^{\circledR}$ on a spool' presents opportunities for MIM producers. Powder Injection Moulding International, 12(3), 83-87.

Burkhardt, C., Freigassner, P., Weber, O., Imgrund, P., \& Hampel, S. (2016). Fused filament fabrication (FFF) of 316L Green Parts for the MIM process. In European Congress and Exhibition on Powder Metallurgy. European PM Conference Proceedings (pp. 1-7). The European Powder Metallurgy Association.

Courtesy McKinsey \& Company (2018). McKinsey report places MIM in top ten 'technologies of the future. Powder Injection Moulding International, 12(2), 7.

Digital Metal (2019). What is additive manufacturing? Retrieved from https://digitalmetal.tech/homedigital-metal/am-metal-technologies/

Dizon, J. R. C., Espera, A. H., Chen, Q., \& Advincula, R. C. (2018). Mechanical characterization of 3Dprinted polymers. Additive Manufacturing, 20, 44-67.

ExOne (2016). Customised and low volume 316L stainless steel firearms components using Binder Jetting technology. Powder Injection Moulding International, 10(4), 69-72.

ExOne (2018). What is Binder Jetting? Retrieved from https://www.exone.com/Resources/TechnologyOverview/What-is-Binder-Jetting

Gibson, M. A., Mykulowycz, N. M., Shim, J., Fontana, R., Schmitt, P., Roberts, A., \& Myerberg, J. S. (2018). 3D printing metals like thermoplastics: Fused filament fabrication of metallic glasses. Materials Today, 21(7), 697-702.

Gonzalez-Gutierrez, J., Kukla, C., Schuschnigg, S., Duretek, I., Holzer, C., \& Ausseninstitut, M. L. (2016). Fused Filament Fabrication for Metallic Parts. In 25. Leobener Kunststoff-Kolloquium: Kunststoffgerechte Bauteilentwicklungvom Werkstoff zum Produckt. Montanuniversitaet Leoben.

Gorodetskii, M. A., Nelyub, V. A., Malysheva, G. V., Shaulov, A. Y., \& Berlin, A. A. (2018). Technology of Forming and the Properties of Reinforced Composites Based on an Inorganic Binder. Russian Metallurgy (Metally), 13, 1195-1198.

Hamidi, M. F. F. A., Harun, W. S. W., Khalil, N. Z., Ghani, S. A. C., \& Azir, M. Z. (2017, October). Study of solvent debinding parameters for metal injection moulded 316L stainless steel. In IOP Conference Series: Materials Science and Engineering (vol. 257, no. 1, p. 012035). IOP Publishing.

Johnson, P. K. (2018). Metal injection molding trends-2018. International Journal of Powder Metallurgy, 54(1), 15. 
Kong, X., Barriere, T., \& Gelin, J. C. (2012). Determination of critical and optimal powder loadings for 316L fine stainless steel feedstocks for micro-powder injection molding. Journal of Materials Processing Technology, 212(11), 2173-2182.

Korotchenko, A.J., Kotomin, S.V., Tverskoy, M.V., Khilkov D.E., Shabeko A.A. (2018) The development of a new composition of the metal powder mixture to injection molding (MIM technology). Liteinoe proizvodstvo (Foundry, Technologies and Equipment), 2, 23-27.

Kukla, C., Duretek, I., Schuschnigg, S., Gonzalez-Gutierrez, J., \& Holzer, C. (2016). Properties for PIM Feedstocks Used in Fused Filament Fabrication. World PM2016-AM-Deposition Technologies.

Kuznetsov, V. A., Shchedrin, A. V., \& Korovin, A. V. (2018). Investigation of Cutting Processes and Surface of Plastic Deformation in Environment of LCTE with Nanosize Antifriction Particles. In International Conference on Industrial Engineering (pp. 1583-1589). Springer, Cham.

Lednev, V. N., Sdvizhenskii, P. A., Asyutin, R. D., Tretyakov, R. S., Grishin, M. Y., Stavertiy, A. Y., \& Pershin, S. M. (2019). In situ multi-elemental analysis by laser induced breakdown spectroscopy in additive manufacturing. Additive Manufacturing, 25, 64-70.

Lengauer, W., Duretek, I., Fürst, M., Schwarz, V., Gonzalez-Gutierrez, J., Schuschnigg, S., \& Morrison, V. (2019). Fabrication and properties of extrusion-based 3D-printed hardmetal and cermet components. International Journal of Refractory Metals and Hard Materials, 82, 141-149.

Lychev, S. A., Kostin, G. V., Koifman, K. G., \& Lycheva, T. N. (2018, April). Modeling and optimization of layer-by-layer structures. In Journal of Physics: Conference Series (vol. 1009, no. 1, p. 012014). IOP Publishing.

Moritz, T., Müller-Köhn, A., Abel, J., Scheithauer, U. and Weingarten, S. (2018). Ceramic Injection Moulding and Ceramic Additive Manufacturing side by side: Opportunities and challenges. Powder Injection Moulding International, 12(4), 77-84.

Munsch, M., Schmidt-Lehr, M., \& Wycisk, E. (2018). Metal additive manufacturing with sinter - based technologies. AmpowerGmbH\&Co, vol. 3 (October).

Ngo, T. D., Kashani, A., Imbalzano, G., Nguyen, K. T., \& Hui, D. (2018). Additive manufacturing (3D printing): A review of materials, methods, applications and challenges. Composites Part B: Engineering, 143, 172-196.

Petzoldt, F. (2018). Metal Injection Moulding in Europe - Technologocal trends and business situation. WORLDPM2018 Congress, Beijing, China, September 16-20.

Raymond, V. (2012). Metal injection molding development: modeling and numerical simulation of injection with experimental validation (Doctoral dissertation, École Polytechnique de Montréal).

Raza, M. R., Ahmad, F., Muhamad, N., Sulong, A. B., Omar, M. A., Akhtar, M. N., \& Aslam, M. (2016). Effects of solid loading and cooling rate on the mechanical properties and corrosion behavior of powder injection molded 316 L stainless steel. Powder Technology, 289, 135-142.

Williams, B. (2018). WORLDPM2018 Congress: Global MIM markets show healthy growth. Powder Injection Moulding International, 12(4), 67-74.

Williams, N. (2018). Threat or opportunity? The MIM industry as a partner, a target and a market for metal AM. Powder Injection Moulding International, 12(4), 57-64.

Wolff, M., Mesterknecht, T., Bals, A., Ebel, T., \& Willumeit-Römer, R. (2019). FFF of Mg-Alloys for Biomedical Application. In Magnesium Technology 2019 (pp. 43-49). Springer, Cham.

Wu, G., Langrana, N. A., Sadanji, R., \& Danforth, S. (2002). Solid freeform fabrication of metal components using fused deposition of metals. Materials \& Design, 23(1), 97-105.

Zheng, R., Tanner, R. I., \& Fan, X. J. (2011). Injection molding: integration of theory and modeling methods. Springer Science \& Business Media, Berlin.

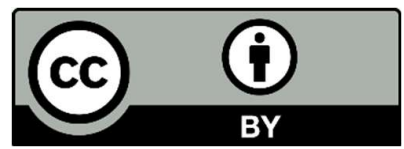

(C) 2020 by the authors; licensee Growing Science, Canada. This is an open access article distributed under the terms and conditions of the Creative Commons Attribution (CC-BY) license (http://creativecommons.org/licenses/by/4.0/). 